\title{
KETAMINE-INDUCED CATALEPTOGENIC EFFECTS IN THE RABBIT: POTENTIATION AND ANTAGONISM ${ }^{1}$
}

\author{
L. AUTHER, M.SC, M.D., A. SINDON, M.D., C.S.P.Q., F.R.C.P.(c), \\ R. Chapados, M.D., C.S.P.Q., C.S.C.R., AND P.P. BARRY, M.D., C.S.P.Q., C.S.C.R."
}

Catatony is an important component of drug-induced extrapyramidal syndromes. Its manifestation in the patient are inactivity and long-sustained abnormal attitudes and some hyperkinetic symptoms such as hysteria-like crises, oculogyric crises and opisthotonos, negativistic behaviour and organo-vegetative phenomena. The complexity of the catatonic syndrome precludes simple experimental quantification. In animal experimentation, one must then rely on catalepsy, a component of catatony, which is more easily measurable. ${ }^{1-4}$

Beaulnes" states: "In catelepsy, the preservation of the muscle tone is a prerequisite for the maintenance of the abnormal attitudes. Catalepsy is, then, an active immobility, a fact well corroborated by electromyographic studies, which differs distinctly from the passive immobility of paralysis. Another essential fact is the maintenance of automatic activity and equilibration reflexes." To complete these definitions let us say that in fundamental pharmacology catalepsy is useful in the screening of neurotropic substances, particularly those of the neuroleptic group. Pharmacological studies of phencyclidine (P.C.P.) and its derivative Ketamine, have shown that they produce the same cataleptogenic effects as the neuroleptics. ${ }^{5}$ We postulate a relation between the extrapyramidal reactions induced by neuroleptics and the muscular phenomena observed after the administration of Ketamine in animals as well as in man. If such a relation exists, we suggest as an hypothesis that drugs which control neuroleptic induced extrapyramidal reactions should also inhibit or somehow modify the cataleptogenic effects of Ketamine in the appropriate animal species.

In animal studies, Chen et al. described phencyclidine and Ketamine as cataleptogenic anaesthetic agents. ${ }^{6, T}$ Their mode of action is imperfectly elucidated. It is thought to be concomitant stimulation and depression of the central nervous system. This results in a wide variation of effects between different species. In the rat and mouse, hyperactivity prevails. On the other hand, when given to the monkey and the dog, phencyclidine and Ketamine induce a cataleptic state which is dose related. The convulsive threshold is raised or lowered depending on species. Physiological responses of the cardiovascular system are unaltered, unless large doses are given. Gastro-intestinal and uterine motility are unchanged. In laboratory animals phencyclidine has greater cataleptogenic potency than Ketamine.

IThis paper was presented at the Annual Meeting of the Canadian Anaesthetists' Society, July 1971 .

Department of Anaesthesia, Maisonneuve Hospital, Montreal,

445

Canad. Anaesth. Sac. J., vol. 19, no. 4, July 1972 
More than ten years ago Greifenstein et al. ${ }^{8}$ and Johnstone et al. ${ }^{9}$ produced their first clinical trials with phencyclidine. This drug was short lived for reasons that will be detailed. It is now popular as a psychedelic drug among young people involved in drug abuse. In 1965 Corssen $^{10}$ and Virtue ${ }^{11}$ introduced Ketamine in clinical anaesthesia. These and other workers put forward the important feature of this drug, which is analgesia and unconsciousness without cardio-respiratory depression. ${ }^{12,13}$ Analgesia appears rapidly but is limited to somatic peripheral sensibility. Following the administration of analgesic doses, the blood pressure and pulse usually rise for some time. Ketamine often produces slight polypnoea and hyperpnoea. Pharyngo-laryngeal reflexes are usually exaccerbated, precluding the stimulation of these regions. The airway is well maintained by preservation of muscular tone. The association of unconsciousness without muscle relaxation gives a distinctive character to Ketamine anesthesia. Should we speak of a state of unconscious vigilance? The apparent discordance between analgesia and unconsciousness on the one hand and the absence of general cerebral depression on the other hand, gave rise to the concept of "dissociative anaesthesia".

On awakening, Ketamine produces psychic stimulation described by some authors as delirium and hallucinations. Luby et al. ${ }^{8}$ define these psychodysleptic effects as perturbation of ego integration, intellectual dysfunction and loss of time and space identification. It is because of these effects that phencyclidine was abandoned shortly after its first appearance in clinical practice. Ketamine is actually better accepted by clinicians, who are less frightened by the hallucinatory phenomena of the awakening period when these effects are of brief duration.

In reviewing the literature on the clinical use of Ketamine, one is amazed by the relative indifference to the muscular phenomena observed during and after anaesthesia. No one would deny the advantages of Ketamine with respect to the cardiorespiratory system, but its use as the sole agent is limited by poor muscular relaxation and, in some patients, hypertonic manifestations which resemble experimental catalepsy. Our goal was first to test our hypothesis that these might be controlled, then to try a method of measurement of catalepsy induced by Ketamine and to apply this method in the search for substances able to modify the cataleptogenic property of the drug.

\section{METHOD}

In this work we adapted a measurement of catalepsy described by Beaulnes and Viens ${ }^{4}$ in their study of neuroleptics. This consists of recording the time a rabbit will take to lift his head after the animal has been placed in the dorsal position with the head fully hyperextended. Ketamine $35 \mathrm{mg} / \mathrm{kg}$ was administered intra-muscularly and the test drugs atropine $1 \mathrm{mg} / \mathrm{kg}$ and procyclidine $2 \mathrm{mg} / \mathrm{kg}$ were given intravenously to separate groups of animals, both being in final concentration to provide $2.5 \mathrm{cc} / \mathrm{kg}$. To the two groups of animals receiving the test drugs we added a placebo group which was given normal saline $2.5 \mathrm{cc} / \mathrm{kg}$ intravenously.

Fifty-four male rabbits of identical strain and weighing from two to three pounds were used in three experiments. In these three experiments the test drugs were administered as follows: (1) thirty minutes before administration of Keta- 
AUTHIER, et al. : KETAMINE-INDUCED CATALEFTOGENIC EFFECTS

TABLE I

Ketamine: Catalepsy in Rabits. Statistical amalysis of Varuance

\begin{tabular}{|c|c|c|c|c|c|c|}
\hline & Source of variation & $\begin{array}{l}\text { Sum of } \\
\text { squares }\end{array}$ & D.L. & $\begin{array}{l}\text { Least } \\
\text { squate }\end{array}$ & $\mathbf{F}$ & $\mathbf{p}$ \\
\hline \multirow{8}{*}{ B } & A : Experimenters & 2.0 & 1 & 2 & 0.9 & n.s. \\
\hline & B : Treatments & 18.8 & 2 & 9.4 & 4.22 & $<0.05$ \\
\hline & $\mathrm{A} \times \mathrm{B}$ & 10.33 & $\mathbf{2}$ & 5.17 & 2.32 & n.s. \\
\hline & Experimental error & 26.66 & 12 & 2.22 & - & - \\
\hline & Total & $\mathbf{5 7 . 7 7}$ & 17 & - & - & - \\
\hline & (Placebo vs Atropine & - & 1 & - & 0 & - \\
\hline & Placebo vs Procyclidine & - & 1 & - & 6.33 & $<0.05$ \\
\hline & (Procyclidine vs Atropine & - & 1 & - & 6.33 & $<0.05$ \\
\hline
\end{tabular}

mine, (2) fifteen minutes before Ketamine and (3) concomitantly with Ketamine.

In each experiment eighteen rabbits were placed in individual cages and then divided into two groups ( $A$ and $S$ ), and each group was randomly given to one observer. Within each group ( $A$ and $S$ ) the animals were divided into three subgroups of six animals each, according to the test drugs administered. In order to satisfy the requirements of the blind technique, the injections to the animals of group A were made by the observer of group $S$ and vice versa; at no time did one observer know which of the test drugs (atropine, procyclidine or placebo) the animals of his group had received.

The observers then proceeded to the evaluation of catalepsy every fifteen minutes in the following way: the animals were placed carefully on their backs on a sloping table and the head was then placed in hyperextension while the hind quarter was maintained with a rubber band. The presence of catalepsy was scored if the animal could preserve this abnormal position for fifteen seconds.

This was a double blind study in which the three items to be compared were randomly distributed, and the observations independently collected, the observers not knowing the previous scores. Furthermore, time and space were kept standard and the observers were the same in all experiments. Results were statistically analysed for variance for two factors from which we could identify, from the total variation, the treatment variation and the observer variation (Table I). Referring to the appropriate table, the null hypothesis was rejected with the determination of corresponding probability of error. The treatment variation was examined in three individual comparisons of placebo versus atropine, placebo versus procyclidine and atropine versus procyclidine.

\section{RESULTS}

The results of the study are illustrated in Figures 1 to 3, in which the duration of catalepsy is indicated in minutes by the height of the columns. Standard errors of the means are represented by the vertical lines at the top of each column. The quantitative values are shown at the base of the columns together with the Fisher's coefficients for the individual comparisons with probabilities of error if necessary ( $\left.\mathrm{p}<0.05 ;{ }^{\circ 0} \mathrm{p}<0.01 ;{ }^{\circ 0} \mathrm{p}<0.001\right)$. 


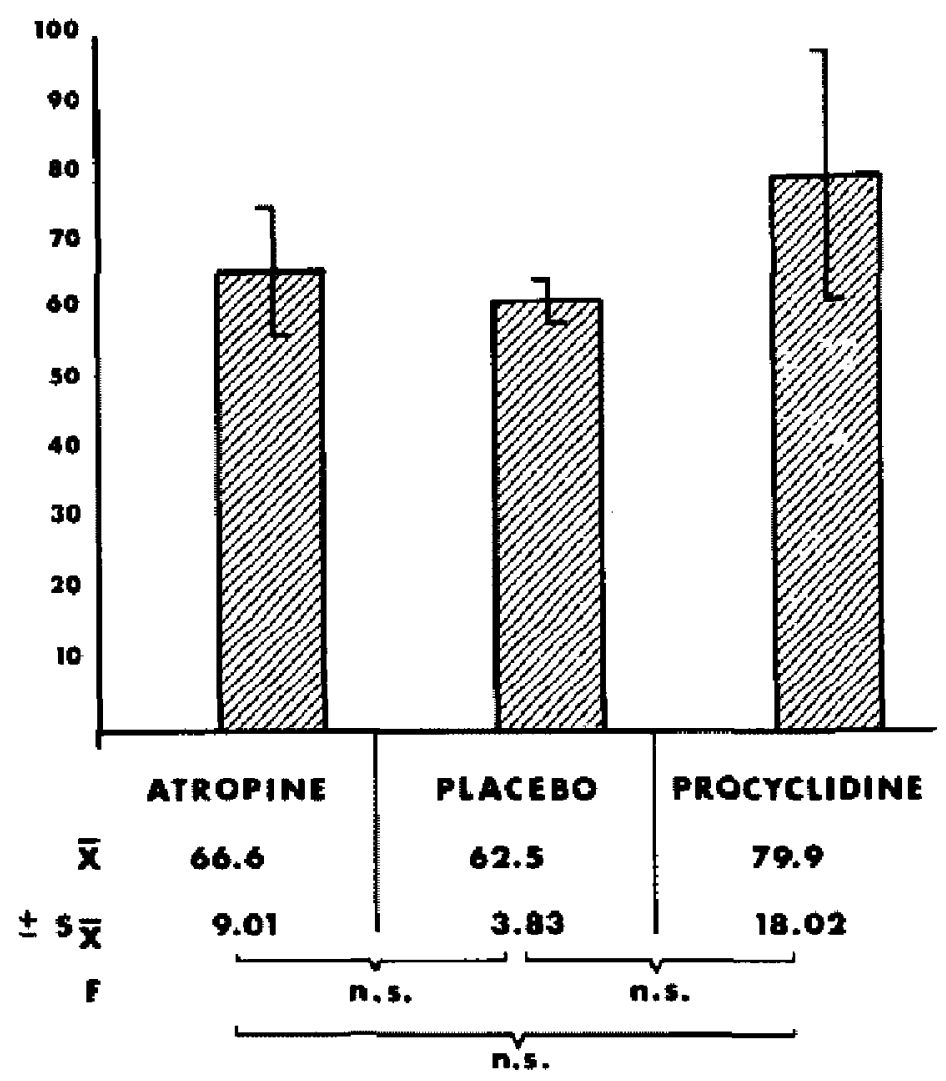

EXP: n.s.

Ficune 1. Comparison of the duration of catalepsy in minutes for placebo and each of the test drugs administered thirty minutes prior to Ketamine. Variation between observers is shown below, and it is noted that it is not significant.

The results of administration of the test drugs thirty minutes before Ketamine are shown in Figure 1. There was a mean duration of 62.5 minutes of catalepsy in the placebo group with a standard error of 3.8. The atropine group had a mean of 66.6 minutes with a standard error of 9.01 and finally the procyclidine group had a mean duration of 79.8 minutes with a standard error of 18 . In the individual comparisons, Fisher's coefficient is too low to indicate a significant difference between these means, although the mean of the procyclidine group is superior. It is evident that there is an important variation within this latter group of animals, the standard error being I8.9.

When the test drugs were given fifteen minutes before Ketamine (Figure 2) the individual comparisons were still not significant. The atropine and procyclidine groups showed means of 69.9 and 72.5 minutes respectively while the placebo group showed 97.5 minutes. This last value is superior to that of the placebo group in the first experiment $(62.5 \mathrm{~min}$.) and again the procyclidine has the widest intra-group variation. 


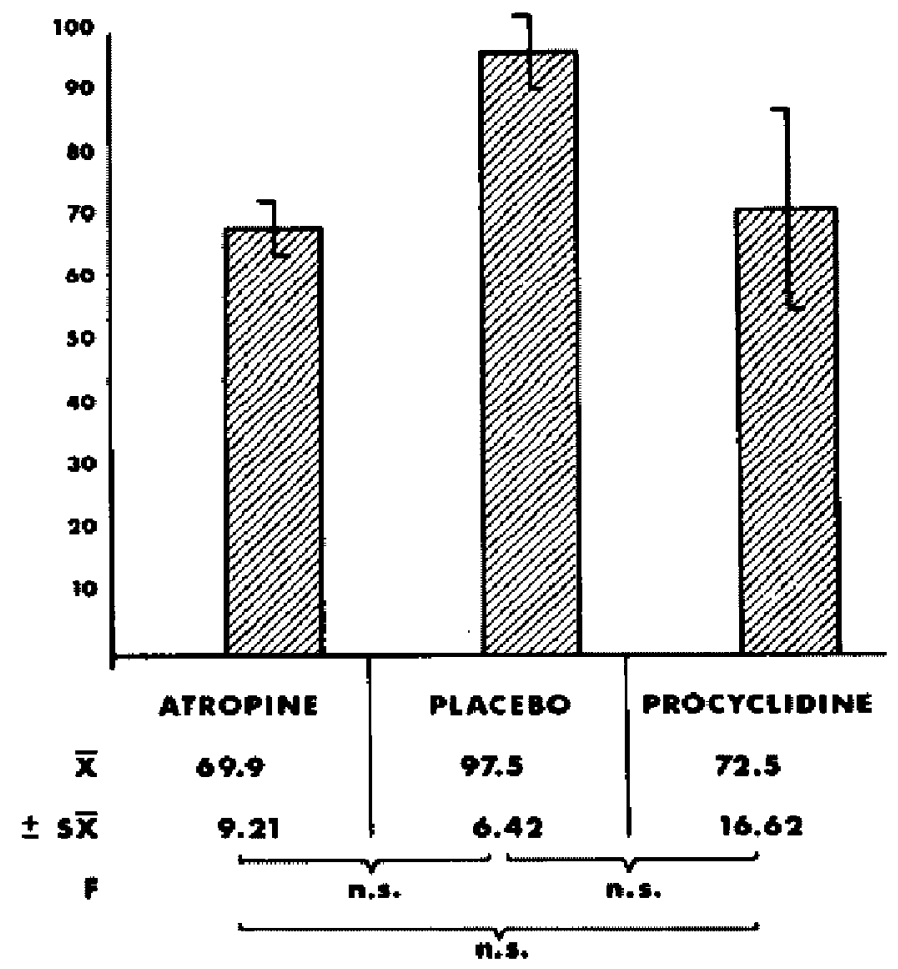

EXP: n.s.

Frcthe 2. Comparison of the duration of catalepsy in minutes for placebo and each of the test drugs administered ffteen minutes prior to Ketamine. Variation between observers is shown below, and it is noted that it is not significant.

Administered concomitantly with Ketamine (Figure 3) the placebo group had a mean of 60 minutes and a standard error of 11.6, the atropine group a mean of 62.4 minutes with a standard error of 6.0 and the procyclidine group a mean of 92.5 and a standard error of 11.8. The comparison between the means of the atropine and the placebo groups are not significant while that of procyclidine is significantly superior to the means of the former two groups with Fisher's coeffcient of 8.33 and 5.45 respectively, both with probabilities of 0.05 .

\section{Discussion}

Chen and McCarthy ${ }^{8}$ reported that phencyclidine has a cataleptogenic effect five times greater than Ketamine and the duration of this effect was shorter with Ketamine. Because of the duration factor we were compelled to use the intramuscular route for Ketamine administration. Only by this route did we obtain a duration of catalepsy long enough to apply the method of measurement used by Beaulnes and Viens. ${ }^{4}$

The leading hypothesis was based on the relation that might exist between 


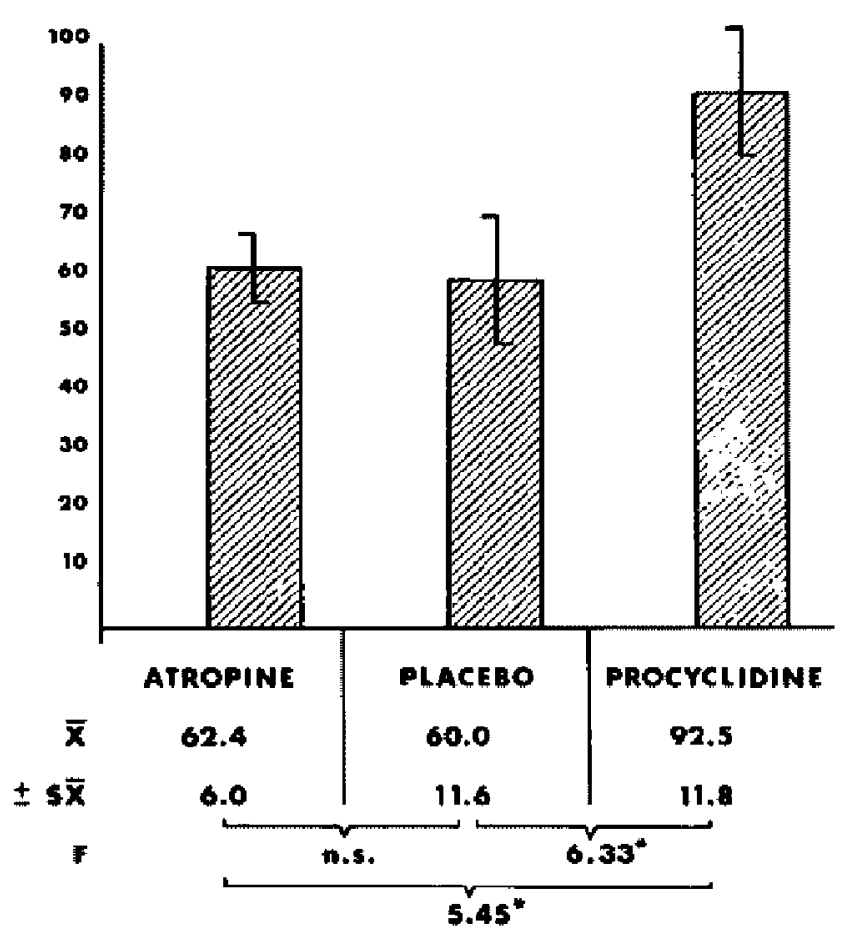

EXP: n.s.

Figure 3. Comparison of the duration of catalepsy in minutes for placebo and each of the test drugs administered concurrent with Ketamine. Variation between observers is shown below. and it is noted that it is not significant.

catalepsy and extrapyramidal syndromes induced by neuroleptics, especially those of the phenothiazine and butyrophenone groups. This possibility guided our choice of the test drugs atropine and procyclidine, both of which are able to control the extrapyramidal reactions of neuroleptics.

In our experimental conditions atropine did not significantly alter the duration of catalepsy in the rabbit. At first sight the dose of $1 \mathrm{mg} / \mathrm{kg}$ of atropine appears to be large, but one must recall that the rabbit metabolises atropine rapidly, due to a specific enzyme. When atropine is given intravenously it is possible that the duration of action is too short to modify the action of Ketamine.

On the other hand, procyclidine $2 \mathrm{mg} / \mathrm{kg}$ prolonged the duration of catalepsy in the animals. If such an effect is tue then it varies from the action observed in the treatment of extrapyramidal reactions. Then the hypothesis initially proposed is challenged. No answer is yet offered to this problem, except perhaps that the relationship between catalepsy and extrapyramidal reactions is poor. Nevertheless many authors ${ }^{1-4}$ hold to the presence of such a relationship. However, there is some divergence of view on methods of measurement of catalepsy. In certain cases it may be difficult to dissociate sleep and sedation from catalepsy. Experi- 
menting with neuroleptics, Courvoisier ${ }^{2}$ has already shown that sedation and catalepsy have different time action kinetics: sedation appears first but is outlasted by catalepsy, which appears later. To conclude properly we would have to invalidate or validate the presence of such a dissociation between catalepsy and sedation in the rabbit treated with Ketamine.

We intend to continue these investigations and to use other test drugs such as amphetamines and L-Dopa, which are useful in the treatment of Parkinson-like reactions. Efforts will be directed to evaluate substances that may possibly control the psychic effect of Ketamine. Such drugs will be useful if they do not antagonise the other advantages of Ketamine.

\section{SUMMARY}

This is a preliminary study undertaken to establish a technique for the measurement of catalepsy in the rabbit and to apply this technique to the evaluation of substances which are able to modify catalepsy induced by Ketamine. Our premises were based on the hypothetical relationship between experimental catalepsy and drug-induced extrapyramidal reactions. If such a relation exists, in our experimental conditions, Ketamine induced catalepsy in the rabbit was not antagonised by procyclidine, which is known to antagonise extrapyramidal reactions induced by neuroleptic drugs.

\section{RÉSUMÉ}

Nous avons présenté un travail préliminaire au cours duquel nous voulions mettre au point une technique de mesure de la catalepsie chez le lapin et appliquer cette méthode pour l'évaluation de substances altérant le pouvoir cataleptogène de la kétamine. S'il existe des rapports entre la catalepsie expérimentale et les syndromes extra-pyramidaux, la procyclidine n'antagonise pas la catalepsie chez le lapin dans nos conditions expérimentales.

\section{REFERENCES}

1. Counvorsife, S., Ducrot, R., \& Jurov, L. Nouveaux aspects expérimentaux de l'nctivité centrale des dérivés de la phénothiazine. Psychotropic Drugs, Garattini \& Ghetti, Elsevier Publishitig Company 373, (1958).

2. Triron, J. Caractérisation générale des effets pharmacodynamiques de substances psy chotropiques, Psychotropic Drugs, Garattini Ghetti, Elsevier Publishing Company 437, (1958).

3. TAFscheser, M. \& Cenlett1, A. Differential Analysis of the Effects of PhenothiazineTranquillizers on Emotional and Motor Behaviour in Experimental Animals. Nature, 184: 823 ( 1959 ).

4. Beaurnes, A. \& Vizns, G. Catatonie et Catalepsie. Système extra-pyramidal et neuroleptiques. Jean-Marc Bordeleatu, Editions Psychiatriques 119 ( 1961 ).

5. CFin, G. Evaluation of Phencyclidine-Type Cataleptic Activity. Arch. Int. Pharmacodyn. 157: 193 ( 1965$)$.

6. Chen, G., Enson, C.R., Russell, D. \& Bohner, B. The Phamacology of 141-Phenylcyclohexyl) Piperidine-HCl. J. Phamacol. Exp. Ther. 127: 241 (1959).

7. Cher, G., Glazxo, A.J, KavMr, D.H. GI-581, Laboratory Summary. Experimental Therapentics Department, Research Division, Parke, Davis \& Company, Ann Arbor, Mich.

8. Greifenstein, F.E, De Vautt, M., Yoshitaxe, J., \& Gajewsix, J.E. A Study of a 1-Aryl Cyclo Hexyl Amine for Anesthesia. Anesth. \& Analg. 37; 283 (1958). 
9. Johnstone, M., Evans, V., \& Beicé, S. Sernyl (CI-395) in clinical Anaesthesia. Brit. J. Anaesth. 31: 433 (1959).

10. Conssen, C. \& Dommo, E.F. Dissociative Anesthesia: Further pharmacologic studies and first clinical experience with the phencyclidine derivative $\mathrm{CI}-581$. Anesth. \& Analg. 45; 29 (1966).

11. Virtue, R.W., Alanis, J.M., Mori, M., Lafargue, R.T., Voger, J.H,K., a Metcalf, D.R. An Anesthetic Agent: 2-Othochlorophenyl, 2-Methylamino Cyclohexanone $\mathrm{HCl}$ (CI581). Anesthesiology. 28: 823 ( 1967 ).

12. Conssen, G., Miynsaxa, M., \& Domino, E.F. Changing Concepts in Pain Control During Surgery: Dissociative Anesthesia with CI-581. Anesth. \& Analg. 47: 746 (1968).

13. Cofss:n, G., Domino, E,F, \& BREE, R.L. Electroencephalographic Effects of Ketamine Anesthesia in Children. Anesth. \& Analg. 48: 1 (1969).

14. WINER, B.J. Statistical Principles in experimental Design. McGraw-Hill Book Company (1982), p. 228.

15. Bosomworta, P.P. Ketamine Symposium - Comments by Moderator. Anesth. \& Analg. 50: $3(1971)$. 